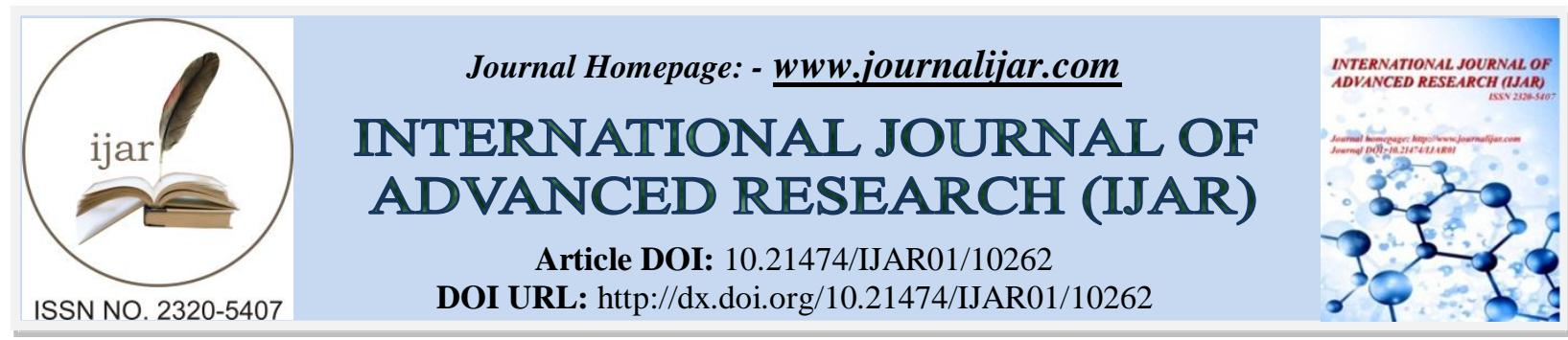

RESEARCH ARTICLE

\title{
PREVALENCE OF TOOTH DISCOLORATION INDUCED BY ENDODONTIC MATERIALS
}

\section{Mohsen Daghustani ${ }^{1}$, Hoda Jehad Abousada ${ }^{2}$, Abdulla Khalid Sagga ${ }^{3}$, Nawaf Al-Hussin Mari Al-Sayed ${ }^{4}$, Muhannad Tariq Abu Al- Nour ${ }^{4}$, Osama Adel Bawazir ${ }^{4}$, Mansour Abdullah Al-Harbi ${ }^{4}$, Mohammed Abdulrahman Khadrawi ${ }^{4}$ and Roaa Mohammad Ali Dwead ${ }^{5}$}

1. Consultant Endodontist Member of the Scientific Council, Saudi Board of Endodontics, Swedish board in Endodontics, Fellowship in Endodontic Microsurgery Jeddah Specialty Dental Centre, Ministry of Health.

2. Medicinae Baccalaureus Baccalaureus Chirurgiae, bn Sina National College, KSA (Postal Address: Jjeddah, Al Thaghr Neigh Bourhood., 22338.

3. General Dentist, Minestry of Health, Riyadh, KSA.

4. BSC, Alfarabi Dental College, Jeddah, KSA

5. Medical Interns, Batterjee Medical College, KSA.

\section{Manuscript Info}

Manuscript History

Received: 15 November 2019

Final Accepted: 22 December 2019

Published: January 2020

\section{Abstract}

Copy Right, IJAR, 2020,. All rights reserved.

\section{Introduction:-}

Endodontic sealing materials for permanent obturation of root canals are highly variable both in chemistry of setting and in their additives. Conventional materials are based on zinc oxide-eugenol, rosin-chloroform, or synthetic resins. These have been extensively tested for biological and technical properties. (Ørstavik, 1998)

One of the most used materials: Gutta percha: It is used in a variety of surgical devices and during root canal therapy. It is the predominant material used to obturate, or fill, the empty space inside the root of a tooth after it has undergone endodontic therapy.

\section{Rationale:}

We will work to have a clear and concise information about the endodontics used frequently in these times and significantly affect the discoloration of teeth. This will help us avoid substances that cause significant and rapid damage in less time to the health of teeth and discoloration.

\section{Literature review:}

There are a few studies in this subject as there are other studies related to part of the subject but represented on bovine model teeth this may not help compared to human teeth.

However, we can mention studies that have benefited us in the reference:

This study:

Assessment of tooth discoloration induced by biodentine and white mineral trioxide aggregate in the presence of blood.

\section{Corresponding Author:- Hoda Jehad Abousada}




\section{The result was:}

The color change was significantly less with biodentine/saline than MTA/saline and MTA/blood (P<0.05). Regardless of the material type and blood presence, discoloration increased after 3 months (P < 0.05). (Adl A, 2019)

Which means that there is a clear influence and change in the color of the teeth of the MTA material this study is very good and compatible with our research since it has also been published recently although it is outside Saudi Arabia.

\section{Another study:}

Tooth crown discoloration induced by endodontic sealers: a 3-year ex vivo evaluation. The result was: All sealers caused discoloration. At 1 month, $\Delta \mathrm{E}$ values were significantly higher in groups 1 and 2 than in groups 3 and 4 $(\mathrm{p}<0.05)$. At 1 year, $\Delta \mathrm{E}$ values were significantly lower in group 3 than in the other groups $(\mathrm{p}<0.05)$. At 3 years, $\Delta \mathrm{E}$ values were significantly higher in group 1 than in the other groups $(\mathrm{p}<0.05)$. (Ekici MA, 2019)

Which means This study was clear for the time it took the teeth be affected and rehearsed after the use of endodontics materials. However, it is not focused on the type of materials, and it is also not established in Saudi Arabia.

The current research aims to determine Prevalence of tooth discoloration induced by endodontic materials.

\section{Research Objectives:-}

1. To determine a relationship between age and discoloration of teeth with endodontic materials

2. To determine a relationship between gender and discoloration of teeth with endodontic materials

3. To determine the most endodontic material used at the present time

4. To determine the most resulting material discoloration teeth

5. Determine the duration since the use of endodontic material until the color of the teeth is shown

\section{Methodology:-}

Study design:

This is an analytical cross-sectional study.

\section{Study Setting and period:}

This is an analytical cross-sectional study conducted in kingdom of saudia Arabia (from the general population IP and OP), from may 2019 till December 2019.

\section{Study population and sampling:}

General population (IP and OP)

\section{Sampling Method:-}

\section{Study Participants:}

Participants were conducted study be carrying the questionnaire during the period of data collection from 11/5/2019 till 12/11/2019. Inclusion criteria; who has already treated his teeth by endodontics materials. Exclusion criteria; other's

\section{Sampling size:}

Sample size was calculated using OpenEpi for sample size calculation for cross sectional studies, hypothesizing the true answers Accordingly, 481 participants were gathered, 35.14\% of the respondents answered that the discoloration occurred in their teeth is differentiate from the natural color.

According to the prevalence study, $20.37 \%$ of the respondents used Gutta percha, and Half of them took more than 1 month. The results indicated that most respondents say either the color has not changed or that it has changed slightly. 


\section{Measurements:-}

Explanatory variables:

1. Sociodemographic characteristics: age, and sex.

2. Disease-related information: Have ever treated by endodontics, name of endodontics material, duration, differentiate of discoloration from the natural color, and description the colour change.

\section{Outcome Measure:}

The outcome measure is by counting the ratio of the number of patients have tooth discoloration this will be measured using:

By determining the extent of the discoloration in addition to the endodontics that lead to suffering from tooth discoloration.

\section{Prevalence study:}

Will be carried to test the questionnaire if easily understood and the response of the participants. Data from the cross-sectional study will be used to calculate the sample size.

\section{Statistical Analysis:}

Data were entered and analyzed using Statistical Package for the Social Sciences (SPSS) version 17. Descriptive statistics were displayed as frequencies and percentages for categorical variables. Measures of central tendencies (the median), and measures and dispersion (minimum - maximum) were used to summarize continuous variables, as the continuous variables were not normally distributed when tested by Shapiro-Wilk test. Univariate analysis was performed to investigate the association between the exposure factors (age, sex, Have ever treated by endodontics, name of endodontics material, duration, differentiate of discoloration from the natural color, and description the colour change.

This was performed using Chi-squared test and Mann-Whitney test. Multivariate analysis to investigate factors independently was performed using binary logistic regression. P value was set at a significance level of $<0.05$.

\section{Results:-}

In this study, the aim was to determine the prevalence of tooth discoloration induced by endodontic materials. 481 patients' participants, were consecutively recruited from in patients' clinics, during a period from 11/5/2019 to $12 / 11 / 2019$

Socio-demographic characteristics of the studied group, The results indicate that most of the respondents are between 16-30 years, The results indicate that most respondents are males. According to disease The results show that most of the respondents treated their teeth by filling the teeth (Endodontics), $20.37 \%$ of the respondents used Gutta percha, Half of the respondents took more than 1 month, $43.66 \%$ of the respondents answered thet the discoloration occurred in their teeth is not diffrentiate from the natural color.

Table 1:- Age.

\begin{tabular}{|l|l|l|l|l|l|}
\hline & & Frequency & Percent & Valid Percent & $\begin{array}{l}\text { Cumulative } \\
\text { Percent }\end{array}$ \\
\hline Valid & Below 10 years & 7 & & & 1.5 \\
\cline { 2 - 6 } & $10-15$ years & 8 & 1.5 & 1.5 & 3.1 \\
\cline { 2 - 6 } & $16-22$ years & 151 & 1.7 & 1.7 & 34.5 \\
\cline { 2 - 6 } & $23-30$ years & 170 & 31.4 & 31.4 & 69.9 \\
\cline { 2 - 6 } & $31-35$ years & 42 & 8.7 & 35.3 & 78.6 \\
\cline { 2 - 6 } & $36-40$ years & 31 & 6.4 & 6.7 & 85.0 \\
\cline { 2 - 6 } & $41-45$ years & 30 & 6.2 & 6.2 & 100.3 \\
\cline { 2 - 6 } & above 45 years & 42 & 8.7 & 8.7 & \\
\cline { 2 - 6 } & Total & 481 & 100.0 & 100.0 & \\
\hline
\end{tabular}




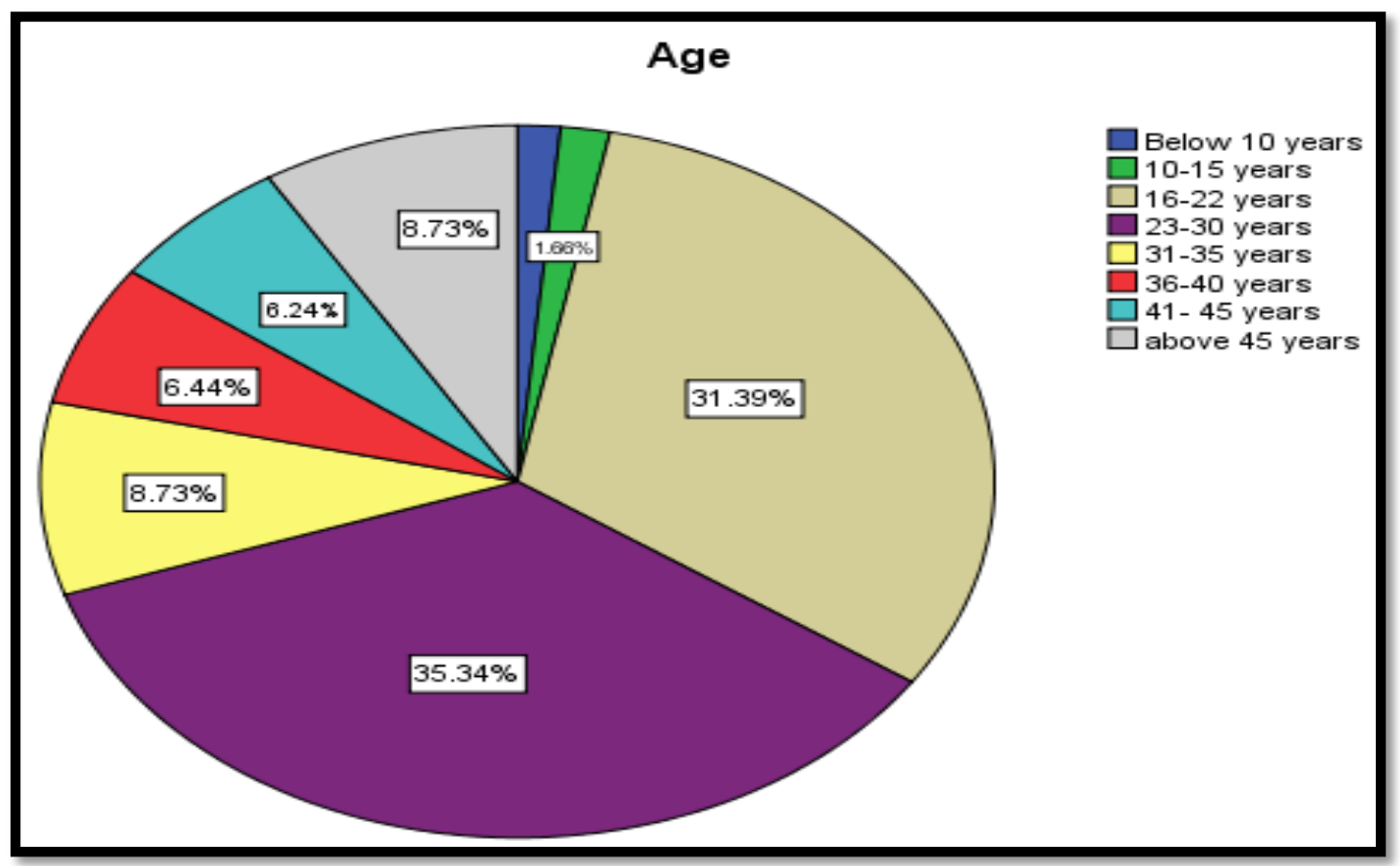

Table 2:- Gender.

\begin{tabular}{|l|l|l|l|l|l|}
\hline & & Frequency & Percent & Valid Percent & Cumulative Percent \\
\hline Valid & Female & 209 & 43.5 & 43.5 & 43.5 \\
\cline { 2 - 6 } & Male & 272 & 56.5 & 56.5 & 100.0 \\
\cline { 2 - 6 } & Total & 481 & 100.0 & 100.0 & \\
\hline
\end{tabular}

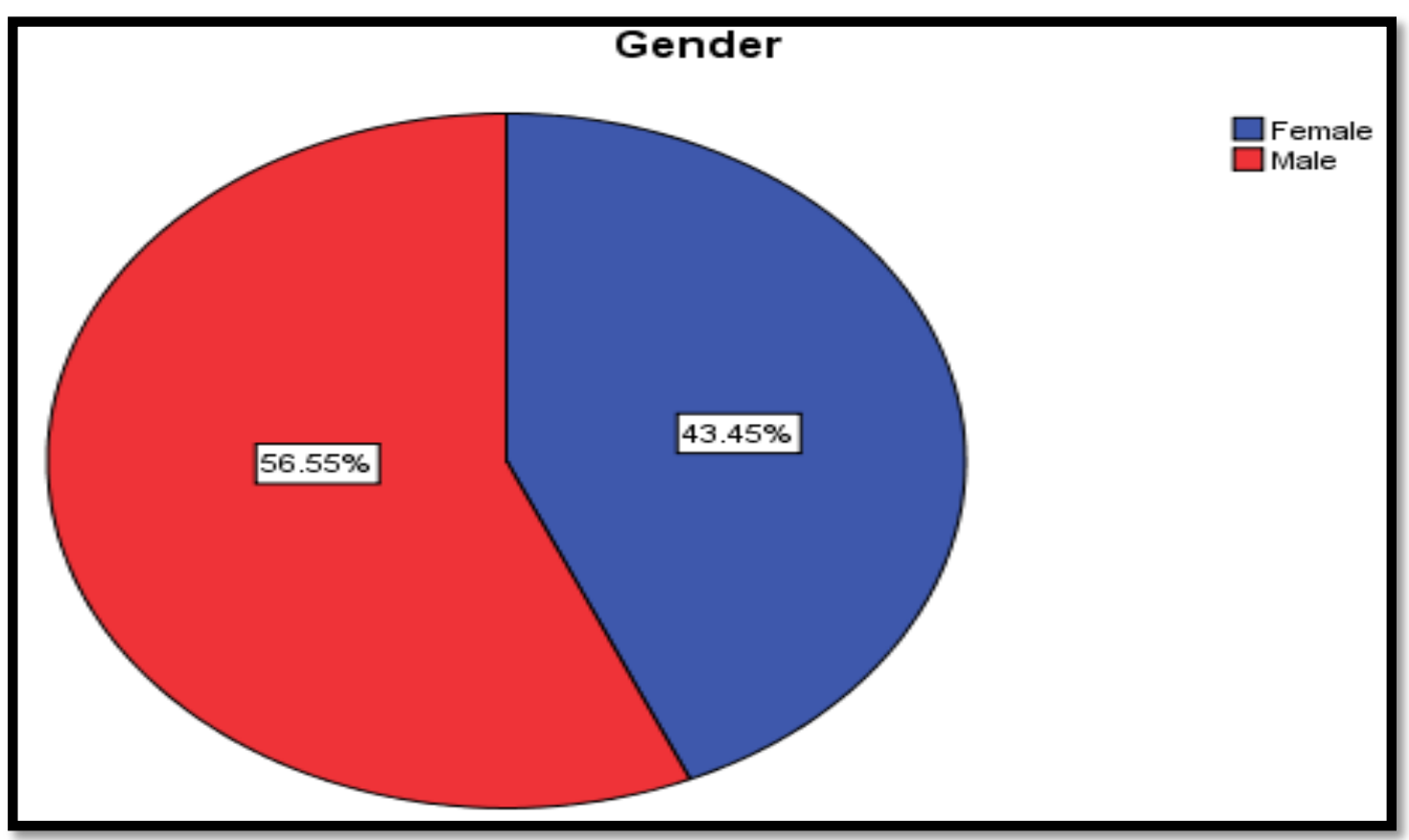


Table 3:- Have you ever treated your teeth by filling the teeth (Endodontics)?

\begin{tabular}{|l|l|l|l|l|l|}
\hline & & Frequency & Percent & Valid Percent & Cumulative Percent \\
\hline \multirow{5}{*}{ Valid } & Yes & 424 & 88.1 & 88.1 & 88.1 \\
\cline { 2 - 6 } & No & 57 & 11.9 & 11.9 & 100.0 \\
\cline { 2 - 6 } & Total & 481 & 100.0 & 100.0 & \\
\hline
\end{tabular}

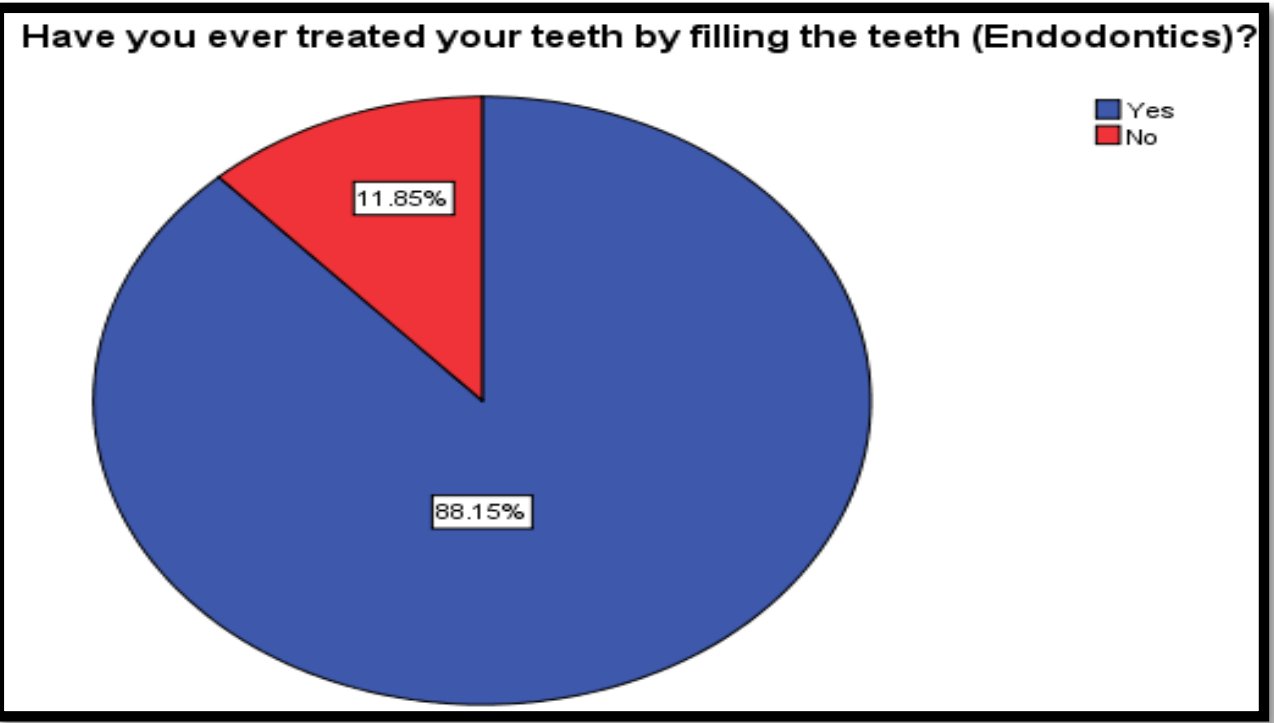

Table 4:- Specify the name of the endodontics material used?

\begin{tabular}{|l|l|l|l|l|l|}
\hline \multirow{3}{*}{ Valid } & Frequency & Percent & Valid Percent & $\begin{array}{l}\text { Cumulative } \\
\text { Percent }\end{array}$ \\
\cline { 2 - 6 } & Gutta percha & & & & 20.4 \\
\cline { 2 - 6 } & Sealers/cements. & 98 & 20.4 & 20.4 & 2.7 \\
\cline { 2 - 6 } & Mineral trioxide aggregate MTA & 18 & 2.3 & 2.3 & 26.4 \\
\cline { 2 - 6 } & I don't know & 354 & 73.6 & 73.6 & 100.0 \\
\cline { 2 - 6 } & Total & 481 & 100.0 & 100.0 & \\
\hline
\end{tabular}

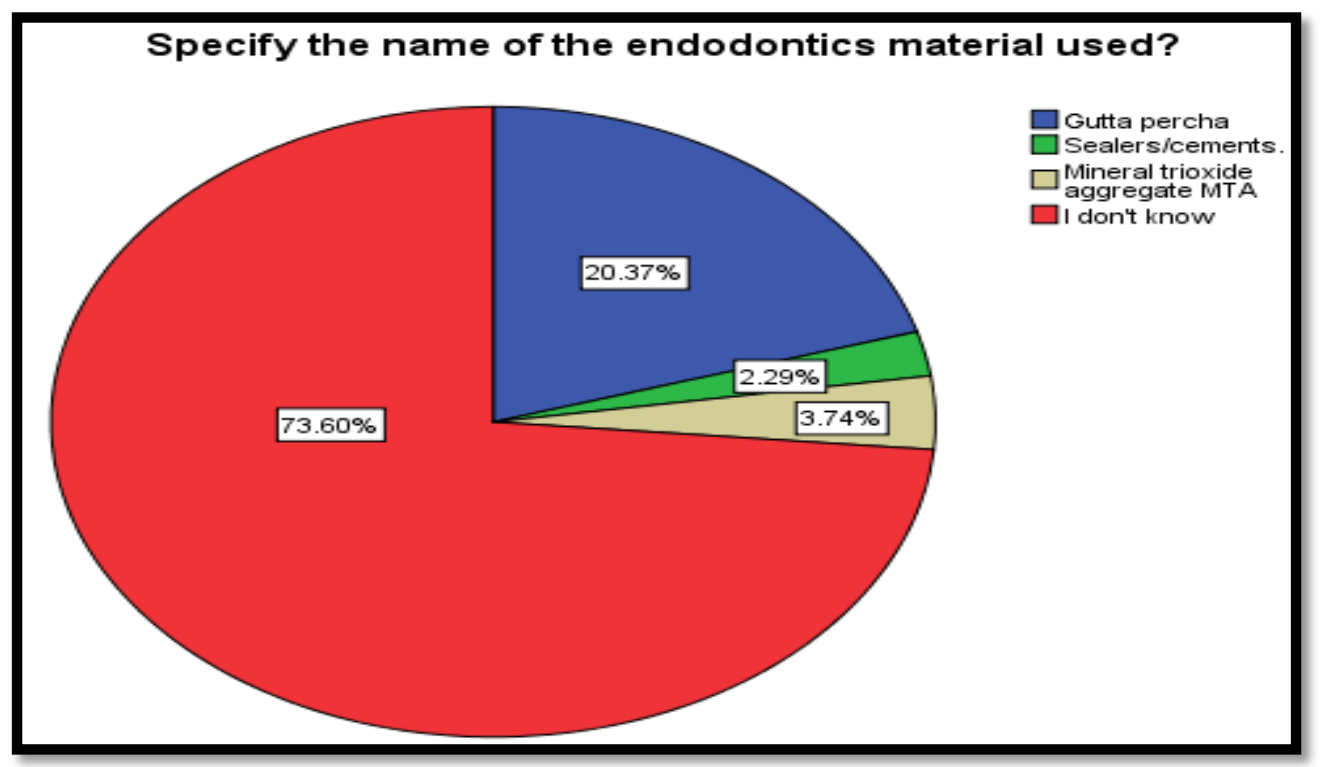


Table 5:- Duration.

\begin{tabular}{|l|l|l|l|l|l|}
\hline & & Frequency & Percent & Valid Percent & $\begin{array}{l}\text { Cumulative } \\
\text { Percent }\end{array}$ \\
\hline \multirow{5}{*}{ Valid } & Less than 1 week & 92 & 19.1 & 19.1 & 19.1 \\
\cline { 2 - 6 } & $1-2$ weeks & 65 & 13.5 & 13.5 & 32.6 \\
\cline { 2 - 6 } & $2-3$ weeks & 42 & 8.7 & 8.7 & 41.4 \\
\cline { 2 - 6 } & $3-4$ weeks & 42 & 8.7 & 8.7 & 50.1 \\
\cline { 2 - 6 } & More than 1 month & 240 & 49.9 & 49.9 & 100.0 \\
\cline { 2 - 6 } & Total & 481 & 100.0 & 100.0 & \\
\end{tabular}

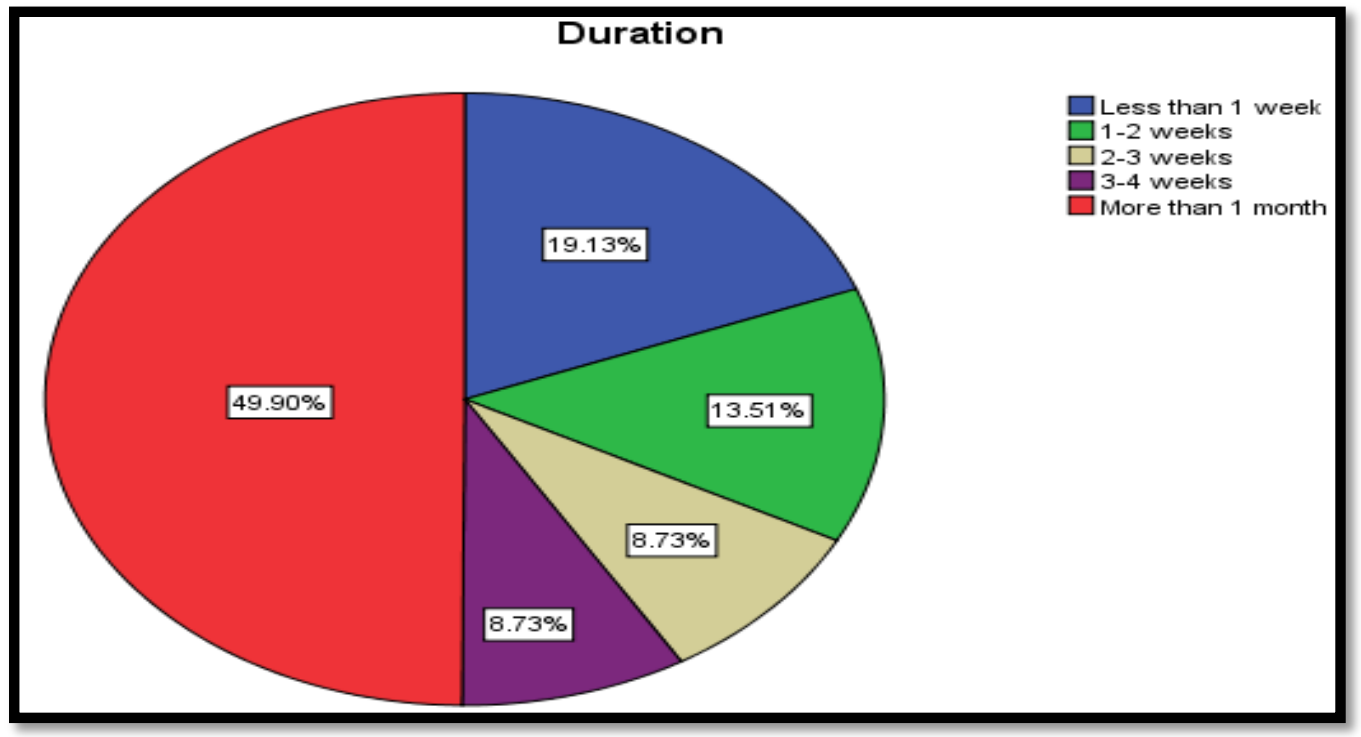

Table 6:- Is discoloration occurred in your teeth differentiate from the natural color?

\begin{tabular}{|l|l|l|l|l|l|}
\hline & & Frequency & Percent & Valid Percent & Cumulative Percent \\
\hline \multirow{5}{*}{ Valid } & Yes & 169 & 35.1 & 35.1 & 35.1 \\
\cline { 2 - 6 } & No & 210 & 43.7 & 43.7 & 78.8 \\
\cline { 2 - 6 } & Maybe & 102 & 21.2 & 21.2 & 100.0 \\
\cline { 2 - 6 } & Total & 481 & 100.0 & 100.0 & \\
\hline
\end{tabular}

Is discoloration occurred in your teeth differentiate from the natural color?

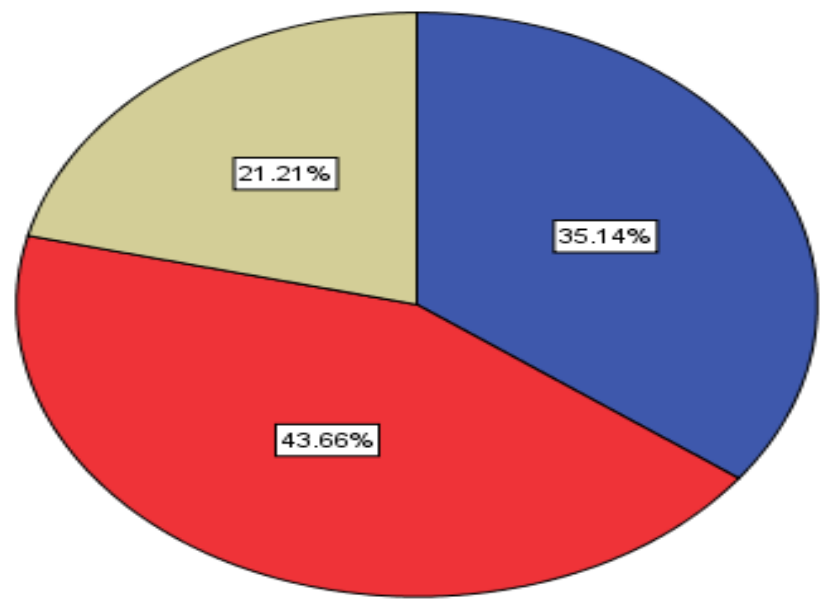


Table 7:- Please describe the color change?

\begin{tabular}{|l|l|l|l|l|l|}
\hline \multirow{3}{*}{ Valid } & Frequency & Percent & Valid Percent & $\begin{array}{l}\text { Cumulative } \\
\text { Percent }\end{array}$ \\
\cline { 2 - 6 } & The color changed slightly & 213 & 44.3 & 44.3 & 44.3 \\
\hline $\begin{array}{l}\text { The color changed very } \\
\text { significantly }\end{array}$ & 64 & 13.3 & 13.3 & 57.6 \\
\cline { 2 - 6 } & The color has not changed & 204 & 42.4 & 42.4 & 100.0 \\
\cline { 2 - 6 } & Total & 481 & 100.0 & 100.0 & \\
\hline
\end{tabular}

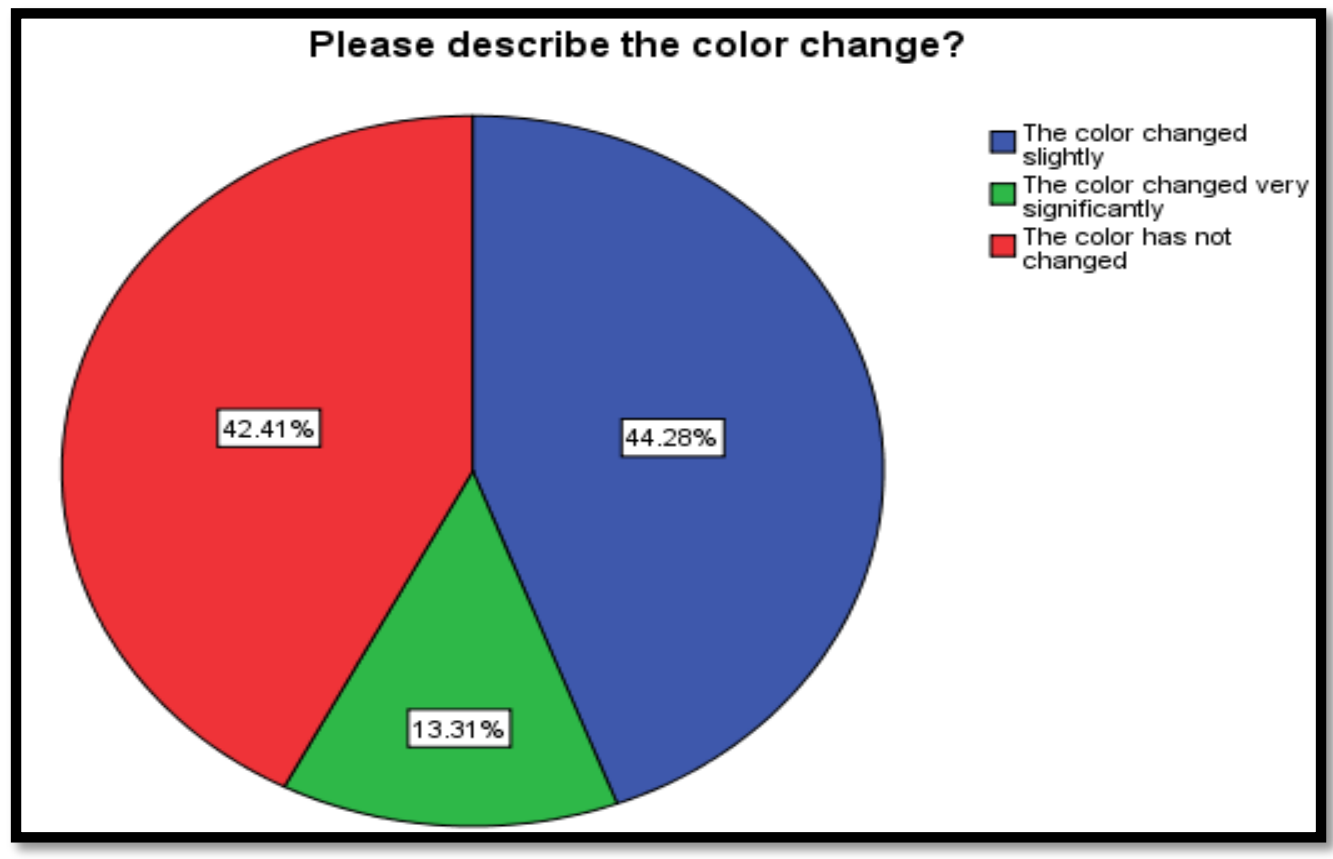

\section{Discussion:-}

This study was based on a number of 481 participants, but to ensure the accuracy of the filling and the correctness of the information entered, a question was asked about have ever treated by endodontics, as the study is limited to discoloration induced by endodontic materials only, otherwise the endodontic substances cause a slight change in the color of the teeth in most of participants.

\section{Conclusion:-}

The responses of the participants in the questionnaire indicated that the endodontic substances cause a slight change in the color of the teeth, and there are a large number of participants who did not notice any change in the color of their teeth.

\section{Recommendation:-}

we recommend setting up health education programs about the dental health and the discoloration by endodontics materials this health problem must be presented broadly and beneficially and, in a way, that everyone understands, as most deal with the tooth discoloration by ignoring and not being important, work should be done on health conferences and medical discussions on that.

\section{Acknowledgement:-}

The authors would like to thank the participant for their great cooperation Dr Baqer Hablan Ali Alsaffar, for collecting data from the (general population). He worked hard to collect data greatly, and a large sample number was collected for his great effort. 


\section{Ethical considerations:-}

Administrative approval will be sought from the unit of biomedical ethics research committee Ethical approval will be sought from the ethical committee of the faculty of medicine, king abdulaziz university. An informed consent will be sought from the participants.

\section{Source of funding, self-funded:-}

This research did not receive any specific grant from funding agencies in the public, commercial, or not-for-profit sectors.

\section{References:-}

1. Ørstavik, D. (1998). Endodontic material. [online] ResearchGate. Available at: https://www.researchgate.net/publication/299461147_Endodontic_material [Accessed Sep. 1988].

2. Adl A, e. (2019). Assessment of tooth discoloration induced by biodentine and white mineral trioxide aggregate in the presence of blood. - PubMed - NCBI. [online] Ncbi.nlm.nih.gov. Available at: https://www.ncbi.nlm.nih.gov/pubmed/31142987 [Accessed 31 Mar. 2019].

3. Ekici MA, e. (2019). Tooth crown discoloration induced by endodontic sealers: a 3-year ex vivo evaluation. PubMed - NCBI. [online] Ncbi.nlm.nih.gov. Available at: https://www.ncbi.nlm.nih.gov/pubmed/30259191 [Accessed 23 May 2019]. 